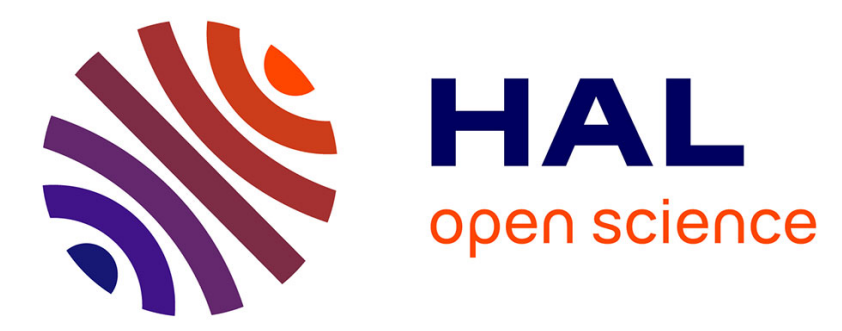

\title{
Evolution of the structural, morphological, optical and electrical properties of reactively RF-sputtered cobalt oxide thin films with oxygen pressure
}

H El Aakib, Jean-François Pierson, M Chaik, C Samba Vall, H Ait Dads, A Narjis, A Outzourhit

\section{To cite this version:}

H El Aakib, Jean-François Pierson, M Chaik, C Samba Vall, H Ait Dads, et al.. Evolution of the structural, morphological, optical and electrical properties of reactively RF-sputtered cobalt oxide thin films with oxygen pressure. Vacuum, 2018, 10.1016/j.vacuum.2018.10.065 . hal-03372937

\section{HAL Id: hal-03372937 \\ https://hal.science/hal-03372937}

Submitted on 11 Oct 2021

HAL is a multi-disciplinary open access archive for the deposit and dissemination of scientific research documents, whether they are published or not. The documents may come from teaching and research institutions in France or abroad, or from public or private research centers.
L'archive ouverte pluridisciplinaire HAL, est destinée au dépôt et à la diffusion de documents scientifiques de niveau recherche, publiés ou non, émanant des établissements d'enseignement et de recherche français ou étrangers, des laboratoires publics ou privés. 


\title{
Evolution of the structural, morphological, optical and electrical
}

\section{properties of reactively $\mathrm{RF}$-sputtered cobalt oxide thin films with}

\section{oxygen pressure.}

\author{
H. El aakib ${ }^{1}$, J.F. Pierson ${ }^{2}$, M. Chaik ${ }^{1}$, C. Samba vall ${ }^{1}$, H. Ait Dads ${ }^{1}$, A. Narjis ${ }^{1}$, \\ A. Outzourhit ${ }^{1}$ \\ ${ }^{1}$ Nanomaterials laboratory for energy and the environment, Faculty of Science Semlalia, Cadi Ayyad \\ University, PO Box: 2390, 40000 Marrakech, Morocco. \\ ${ }^{2}$ Institut Jean Lamour (UMR CNRS 7198), Université de Lorraine, Campus ARTEM, 2 allée André \\ Guinier, 54011 Nancy cedex, France. \\ * Corresponding author: E-mail: hind.elaakib@gmail.com
}

\begin{abstract}
Cobalt oxide thin films were deposited on glass and silicon substrates using reactive cathodic radio-frequency sputtering from a pure cobalt target in oxygen/argon gas mixtures with different percentages of oxygen $(10,30,40$ and $50 \%)$. The X-ray diffractograms showed that deposited thin films crystallized in a cubic $\mathrm{Co}_{3} \mathrm{O}_{4}$ phase. The crystallite size was found to vary with the oxygen pressure, reaching a maximum using $40 \%$ of $\mathrm{O}_{2}$. Scanning electron microscopy (SEM), AFM, energy dispersive X-ray spectroscopy and Raman scattering analyses confirmed the formation of $\mathrm{Co}_{3} \mathrm{O}_{4}$ films with nano-sized particles. In addition, it is found that the optical band gap of the films increased with increasing oxygen pressure in the sputtering atmosphere. Finally, the electrical resistivity of the sputtered thin films was shown to increase with oxygen-percentage.
\end{abstract}


Keywords: Cobalt oxide thin films; reactive RF-sputtering; optical properties; structural properties; electrical properties.

\section{Introduction}

There is an increasing interest in the preparation and the investigation of materials with novel structural features and properties. Among these, transition metal oxides crystallizing in the spinel-type structure offer various optical, electrical and magnetic properties stemming from the multi-valence of the metal cations. In addition, nanostructuration is a promising approach to achieve unique materials properties due to specific surface increase and the effects of confinement [1]-[3].

Among transition metal oxides, cobalt oxide has received a particular interest because of its wide range of properties. Indeed, cobalt oxide $\mathrm{Co}_{3} \mathrm{O}_{4}$ is an antiferromagnetic material that crystallizes in the $\mathrm{Fd} \overline{3} \mathrm{~m}$ space group with a mixed valence for cobalt ions: divalent $\mathrm{Co}^{2+}$ and trivalent $\mathrm{Co}^{3+}$. The oxygen anions $\mathrm{O}^{2-}$ are distributed in a compact cubic stack with centered faces whereas the $\mathrm{Co}^{2+}$ cations occupy the tetrahedral sites and the $\mathrm{Co}^{3+}$ cations occupy half of the octahedral sites [4], [5].

Owing to it unique properties, $\mathrm{Co}_{3} \mathrm{O}_{4}$ thin films have been potentially used in various applications such as thin film supercapacitors [6], selective gas sensor [7], selective absorber for photothermal conversion [8], [9], fuel cells [10], catalysis [11], batteries [12], efficient visible light photocatalysts [13] and magnetic devices [14].

Consequently, several studies were devoted to low cost and environment-friendly techniques for the synthesis of cobalt oxides thin films with improved properties. In this context, different coating techniques were used to prepare the $\mathrm{Co}_{3} \mathrm{O}_{4}$ thin films, such as electrodeposition [15], spin-coating [16], dip coating [17], chemical vapor deposition [18], chemical spray pyrolysis [19] and RF magnetron sputtering [20]. 
The main disadvantages of the wet methods [21] lie in their incompatibility with device processing techniques, and limited flexibility in substrate choice, the inability to control growth of the films, and their limited capabilities for large-scale production. Physical processes such as reactive RF sputtering technique overcome these limitations and offer many advantages such as process reliability, production of high quality and uniform thin films with the desired chemical composition at industrial scale [22] and has a very high level of reproducibility unlike to the others mentioned methods. In addition, reactive sputtering allows to easily control the stoichiometry of the oxides and to deposit multi-layers of different compositions that can be tailored for specific applications (i.e., selective absorbers for solar applications).

In this work, reactive RF-sputtering method was used to make a further study the effect of oxygen pressure on structural, morphological, electrical and optical properties of sputtered cobalt oxide thin films. To the best of our knowledge, X-ray reflectometry is used for the first time in this work to follow the evolution of the density of the films with oxygen percentage in the sputtering chamber

\section{EXPERIMENTAL DETAIL}

\subsection{Deposition of cobalt oxide thin films}

Cobalt oxide thin films were deposited at ambient temperature by reactive RF sputtering on glass and silicon substrates that were beforehand ultrasonically cleaned in acetone and distilled water during $15 \mathrm{~min}$. Before the sputtering process, the vacuum pressure in the chamber was lower to $10^{-6}$ mbar. A pure metallic cobalt target $(12 \mathrm{~cm}$ diameter and $0.2 \mathrm{~cm}$ thick with a purity of $99.99 \%$ ) was pre-sputtered for 15 min and used to deposit the $\mathrm{Co}_{3} \mathrm{O}_{4}$ thin films. The substrate-target distance was fixed at $7 \mathrm{~cm}$. The reactive sputtering was carried out in an $\mathrm{Ar} / \mathrm{O}_{2}$ gas mixture with different $\mathrm{O}_{2}$ percentages (10, 30, 40 and $50 \%$ ). The total pressure was $1 \mathrm{~Pa}$ while the RF-power was fixed at $200 \mathrm{~W}$. 


\subsection{Characterization techniques}

The crystal structure of obtained $\mathrm{Co}_{3} \mathrm{O}_{4}$ thin films was investigated by Rigaku Smart lab SE $\mathrm{X}$-ray diffractometer in the $2 \theta$ range of $20-80^{\circ}$ with a $\mathrm{CuK} \alpha$ radiation in the Bragg Brentano configuration $(\lambda=1.5418 \AA$ ). Raman spectroscopy (Confotec - Model MR520 - 3D Scanning Laser Raman Confocal Microscope) technique was used to identify all the obtained phases. The surface topography of sputtered thin films was studied by an NTEGRA atomic force microscope (NT-MDT). The grain sizes were determined by the nova software that allows the visualization of data from atomic force microscopy. The elemental composition of films was determinate by using the Energy Dispersive X-Ray Spectroscopy (EDS - SSD Bruker). The optical properties were measured in the $500-2500 \mathrm{~nm}$ wavelength-range using an UV-VisNIR spectrometer (Varian Cary 5000). A profilometry technique was used to measure the thickness of the deposited films. The electrical resistivity of the obtained films was measured by the 4-point method using a Keithly 6430 sub-femtoamp remote source meter.

\section{Results and discussion}

\subsection{X-ray diffraction study}

Fig. 1 shows the X-ray diffractograms of thin films deposited on glass at different oxygen percentages. The diffractograms indicate that all the as-deposited films are nanocrystallized. The diffraction peaks observed at $2 \theta$ values of $30.81,36.36,38.2$ and $44.32^{\circ}$ are attributed to the (220), (311), (222) and (400) lattice planes of face centered cubic structure of $\mathrm{Co}_{3} \mathrm{O}_{4}$ with a space group Fd $\overline{3} m$ (ref code: $80-1533$ ). No impurity peaks are observed thus indicating the formation of the $\mathrm{Co}_{3} \mathrm{O}_{4}$ phase is favored under these conditions. The crystalline quality of the films decreases for oxygen pressures greater than $40 \%$ as revealed by the decrease in intensity and the increase in the full width at half maximum (FWHM) value of the peak (311). All the structural parameters such as lattice parameter, d-spacing, crystallite size and strain of the 
sputtered films are calculated from the XRD analysis and are listed in Table 1. The lattice parameter, $a$, was calculated by using the following formula [23]:

$$
d_{h k l}=\frac{a}{\sqrt{h^{2}+k^{2}+l^{2}}}
$$

Where $\mathrm{d}_{\mathrm{hkl}}$ is the lattice spacing and $h, k, l$ are the Miller indices. The obtained lattice parameter varies from 8.09 to $8.13 \AA$ by varying the oxygen percentage. This is in agreement with the results obtained in the JCPDF files (ref code: 80-1533). The crystallite size, $D$, of all the sputtered films was calculated by using Debye-Scherrer formula [24]:

$$
D=\frac{0.94 \lambda}{\beta \cos \theta}
$$

Where $\lambda$ is the wavelength of $\mathrm{Cu}-\mathrm{K} \alpha$ radiation $(1.5418 \AA)$ and $\beta$ is the full width at the halfmaximum (FWHM). The crystallite size increases with increasing oxygen pressure reaching the maximum at $40 \% \mathrm{O}_{2}$, which indicates the improvement of crystallinity. The crystallite size starts to decrease when the oxygen content exceeds $40 \%$. On the other hand, the strain, $\varepsilon$, of the sputtered $\mathrm{Co}_{3} \mathrm{O}_{4}$ thin films is calculated from the following equation [25]:

$$
\varepsilon=\frac{\beta \cos \theta}{4}
$$

It was observed that the strain in the obtained films decreases with increasing pressure of $\mathrm{O}_{2}$ until $40 \% \mathrm{O}_{2}$ and starts to increase. This shows that the increase in crystallite size is correlated with the decrease in strain, which indicates a decrease in lattice imperfections and formation of high-quality films.

According to XRD analyses, the $40 \%$ oxygen pressure is therefore considered optimal for the growth of $\mathrm{Co}_{3} \mathrm{O}_{4}$ films with good crystalline quality under these conditions (200W) by increasing the deposition energy and consequently gives a large crystallite size. 


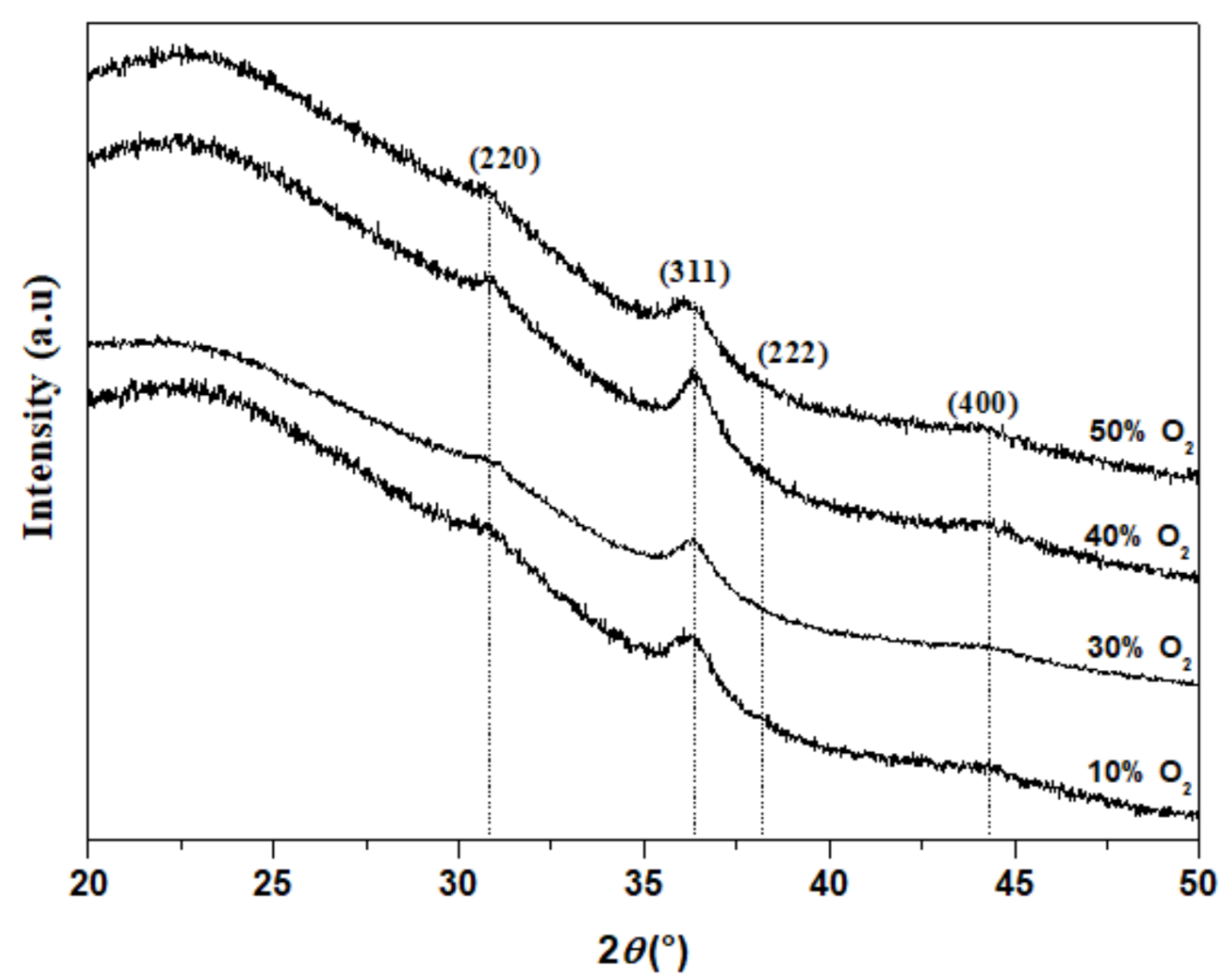

Fig. 1. X-ray diffractograms of $\mathrm{Co}_{3} \mathrm{O}_{4}$ thin films deposited using different oxygen percentages.

Table 1. Structural parameters derived from XRD measurements of $\mathrm{Co}_{3} \mathrm{O}_{4}$ thin film films.

\begin{tabular}{|c|c|c|c|c|c|c|c|}
\hline $\begin{array}{c}\text { Oxygen } \\
\text { pressure } \\
(\%)\end{array}$ & Orientation & $\begin{array}{l}\mathbf{2 \theta} \\
\left(^{\circ}\right)\end{array}$ & $\begin{array}{c}\text { FWHM } \\
\left(^{\circ}\right)\end{array}$ & $\begin{array}{c}\text { Crystallite } \\
\text { Size } \\
D(\mathbf{n m}) \\
\end{array}$ & $\begin{array}{l}\text { Strain } \\
\left(\times 10^{-3}\right)\end{array}$ & $\begin{array}{c}\text { Lattice } \\
\text { parameter } \\
(\AA)\end{array}$ & $\begin{array}{c}\text { d- } \\
\text { spacing } \\
(\AA)\end{array}$ \\
\hline 10 & (311) & 36.36 & 0.95 & 8.74 & 4.14 & 8.13 & 2.45 \\
\hline 30 & (311) & 36.36 & 0.83 & 10.01 & 3.62 & 8.10 & 2.44 \\
\hline 40 & (311) & 36.36 & 0.69 & 12.04 & 3.01 & 8.08 & 2.44 \\
\hline 50 & (311) & 36.36 & 0.76 & 10.93 & 3.31 & 8.09 & 2.44 \\
\hline
\end{tabular}

\subsection{X-ray reflectometry}

The X-ray reflectance $R(\alpha)$ spectra of the all sputtered films are plotted in Fig. 2. These curves show a single stage of total reflection, which supports the homogeneity of the obtained films. The critical angle for total internal reflection $\left(\alpha_{c}\right)$ corresponds to the inflection point of the reflectance curve. This angle is related to the electronic density of the material, and then 
its density, by the following equation:

$$
\alpha_{c}=\sqrt{\frac{N_{a} r_{e} \lambda^{2} \rho_{e}}{\pi}}
$$

Where $r_{e}$ is the classical electron radius $r_{e}=\frac{e^{2}}{4 \pi \varepsilon_{0} m c^{2}}=2.82 \times 10^{-15} \mathrm{~m}, \lambda$ is the wavelength of $\mathrm{Cu}-\mathrm{K} \alpha$ radiation $(1.5413 \AA), \rho_{e}$ is the electronic density, which is given by a weighted sum of the contributions of the various elements of the compound. The electronic density is related to the density $\rho$ of the material by:

$$
\rho_{\mathrm{e}}=\rho \frac{\sum_{i=1}^{N} c_{i} f_{1 i}}{\sum_{i=1}^{N} c_{i} M_{i}}
$$

where $N$ is the number of elements in the formula of the compound, $c_{i}$ is the stoichiometric coefficient of the element, $M_{i}$ is its molar mass and $\mathrm{f}_{1 \mathrm{i}}$ is the dispersive component of the $\mathrm{X}$ ray atomic scattering factor for $\mathrm{Cu}-\mathrm{K} \alpha$ of element [26].

The uncertainty in density calculation was determined by:

$$
\rho_{e}=\frac{\pi \alpha_{c}^{2}}{N_{a} r_{e} \lambda^{2}}
$$

by neglecting the uncertainty in the other factors, we have:

$$
\frac{\Delta \rho_{e}}{\rho_{e}}=2 \frac{\Delta \alpha_{c}}{\alpha_{c}}
$$

Typically, the uncertainty in the measured angle is less than $0.005^{\circ}$ since the resolution of the instrument is $0.001^{\circ}$, yielding a relative uncertainty of less than $4 \%$ [27].

The critical angle corresponds to the position of the minimum of the derivative $d R(\alpha) / d \alpha$ of the reflectivity (Fig. 3). The results clearly indicate that the critical angle and consequently the density of the films increase with increasing oxygen pressure (Fig. 4). The density of the films tends towards the bulk value of $\mathrm{Co}_{3} \mathrm{O}_{4}\left(6.1 \mathrm{~g} / \mathrm{cm}^{3}\right)$ as the oxygen pressure is increased. The 
difference between thin film and bulk density is usually attributed to the grain boundaries in polycrystalline thin films. In addition, the presence of an amorphous will also reduce the effective density of the film as amorphous materials have lower densities (30\%) lower than their crystalline counterparts due the presence of voids [28]. The presence of a nonstoichiometric surface layers resulting from the interaction of the films with the atmosphere $\left(\mathrm{O}_{2}, \mathrm{H}_{2} \mathrm{O} \ldots\right)$ is not ruled out as this layer may also affect the reflectometry measurements and thus the density [29].

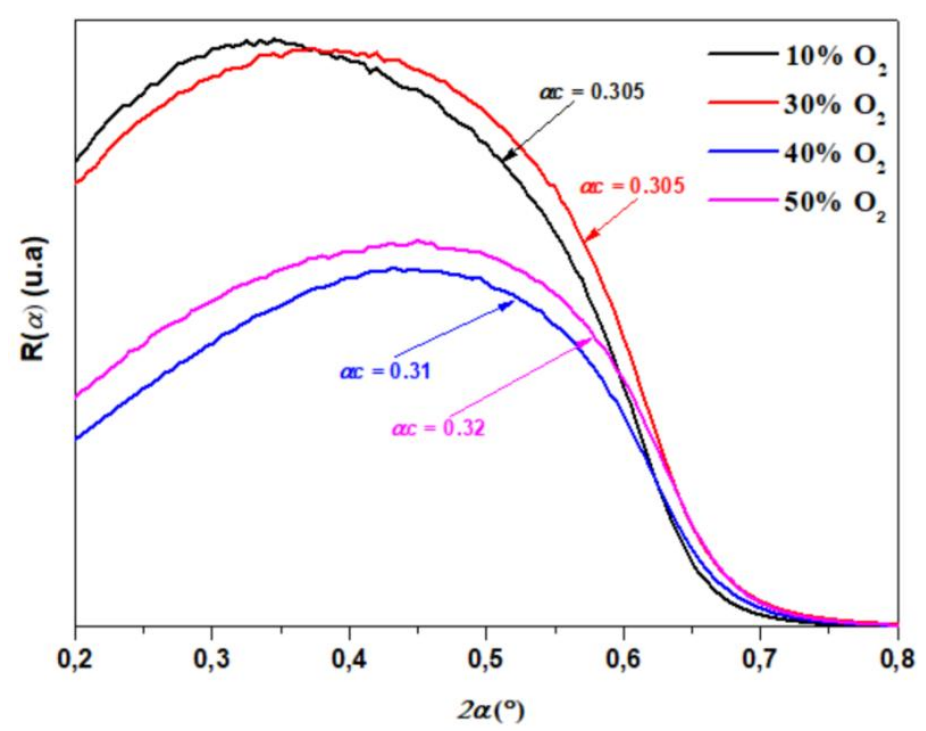

Fig. 2. X-ray reflectometry diagram of $\mathrm{Co}_{3} \mathrm{O}_{4}$ films deposited at various oxygen percentages.

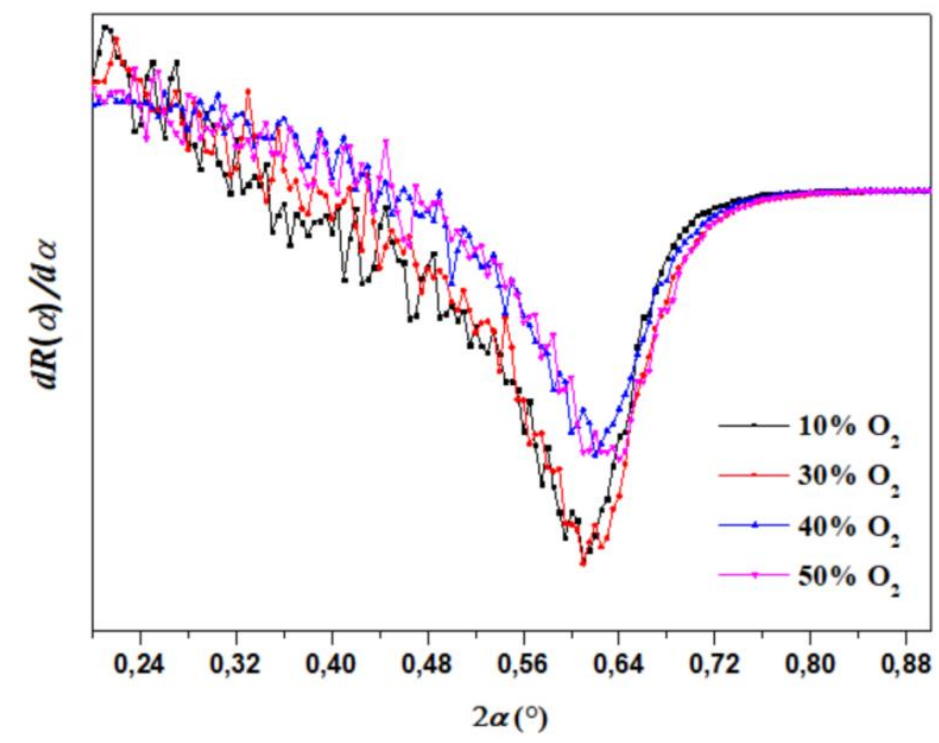

Fig. 3. The derivative curves $d R(\alpha) / d \alpha$ of the $\mathrm{Co}_{3} \mathrm{O}_{4}$ films deposited at different oxygen percentages. 


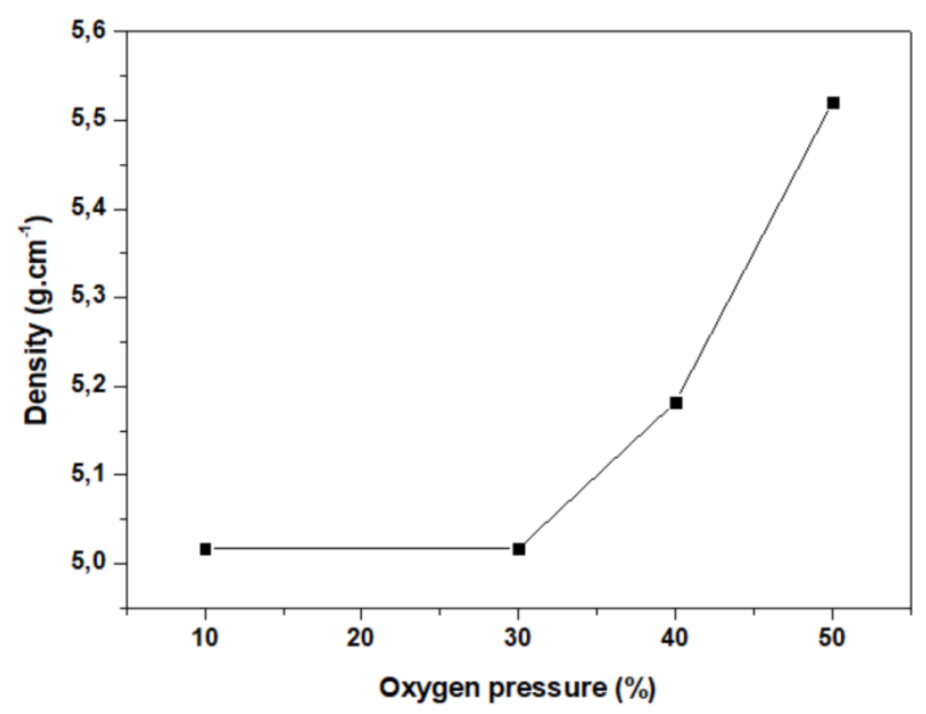

Fig. 4. Evolution of the density as a function of oxygen pressure.

\subsection{Raman data}

The structural properties of $\mathrm{Co}_{3} \mathrm{O}_{4}$ were also investigated by Raman spectroscopy as shown in Fig. 5. Indeed, $\mathrm{Co}_{3} \mathrm{O}_{4}$ has 7 vibrational modes represented as follows:

$$
\Gamma=\mathrm{A}_{1 \mathrm{~g}}+\mathrm{E}_{\mathrm{g}}+3 \mathrm{~F}_{2 \mathrm{~g}}+5 \mathrm{~F}_{1 \mathrm{u}}+2 \mathrm{~A}_{2 \mathrm{u}}+2 \mathrm{E}_{\mathrm{u}}+2 \mathrm{~F}_{2 \mathrm{u}}
$$

The Raman active modes are $\mathrm{A}_{1 \mathrm{~g}}, \mathrm{E}_{\mathrm{g}}$ and $3 \mathrm{~F}_{2 \mathrm{~g}}$ and Raman inactive modes are $2 \mathrm{~A}_{2 \mathrm{u}}, 2 \mathrm{E}_{\mathrm{u}}$ and $2 \mathrm{~F}_{2 \mathrm{u}}$. In regard to $5 \mathrm{~F}_{1 \mathrm{u}} 4$ are infrared active and the other is an acoustic mode [30], [31]. The Raman spectra of all the prepared thin films on glass substrates show clearly five dominant peaks located at $185,470,506,601$ and $670 \mathrm{~cm}^{-1}$, that are attributed respectively to the fives Raman active modes $\mathrm{E}_{\mathrm{g}}, 3 \mathrm{~F}_{2 \mathrm{~g}}$ and $\mathrm{A}_{1 \mathrm{~g}}$ of $\mathrm{Co}_{3} \mathrm{O}_{4}$ [32]. The $\mathrm{E}_{\mathrm{g}}$ and $3 \mathrm{~F}_{2 \mathrm{~g}}$ mode are attributed to vibration of the $\mathrm{Co}_{3} \mathrm{O}_{4}$ tetrahedral [33] and the $\mathrm{A}_{1 \mathrm{~g}}$ mode is assigned to the symmetric stretching of the Co-O bond in the octahedral sites [33]. Its width is related to the $\mathrm{Co}-\mathrm{O}$ bond lengths distribution and distortion occurring in $\mathrm{Co}_{3} \mathrm{O}_{4}$. The spectra confirm the $\mathrm{Co}_{3} \mathrm{O}_{4}$ spinel structure occurrence for all as-deposited films, where $\mathrm{Co}^{2+}$ and $\mathrm{Co}^{3+}$ occupy the tetrahedral and octahedral sites of $\mathrm{Co}_{3} \mathrm{O}_{4}$, respectively. The corresponding Raman parameters for all the sputtered films and the comparison of their characteristics peaks are summarized in Table 2 .

It is worth noting however, that these peaks are slightly down-shifted to lower wavenumbers 
in comparison with those of the bulk $\mathrm{Co}_{3} \mathrm{O}_{4}$ reported in the literature (ex. $\mathrm{A}_{1 \mathrm{~g}}$ located at $690 \mathrm{~cm}^{-1}$ ). This effect is attributed to heating of the films induced by the Raman excitation laser. This downshift is reduced when the intensity of the laser is reduced or when a silicon substrate is used instead of the glass as result of the high thermal conductivity of silicon. Also, it is noted that the intensity of all the peaks increase with increasing oxygen percentage until $40 \% \mathrm{O}_{2}$ and start to decrease which is in good agreement with the XRD results. The intensity of peaks starts to decrease at $50 \%$ of oxygen pressure. This is may be to the presence of defects in $\mathrm{Co}_{3} \mathrm{O}_{4}$ structure at $50 \% \mathrm{O}_{2}$. This behavior may also be attributed to several parameters such as crystallite size, strain and non-stoichiometry or changes in bond lengths [34]. Furthermore, as-expected the measured FWHM of the Raman peaks of the films is still larger than that observed in bulk crystalline $\mathrm{Co}_{3} \mathrm{O}_{4}$, which is on the order of 5 to $10 \mathrm{~cm}^{-1}$ depending on the peak [35]. This is generally attributed the phonon confinement as results of the small crystallite size. However, narrowing and a shift of the Raman peaks to a higher wavenumbers are also observed as the oxygen pressure increases to $40 \%$ suggesting an improved crystallinity of the film in accordance with the XRD measurements. These results suggest that the films are partially crystallized which is in good agreement with XRD measurements. 


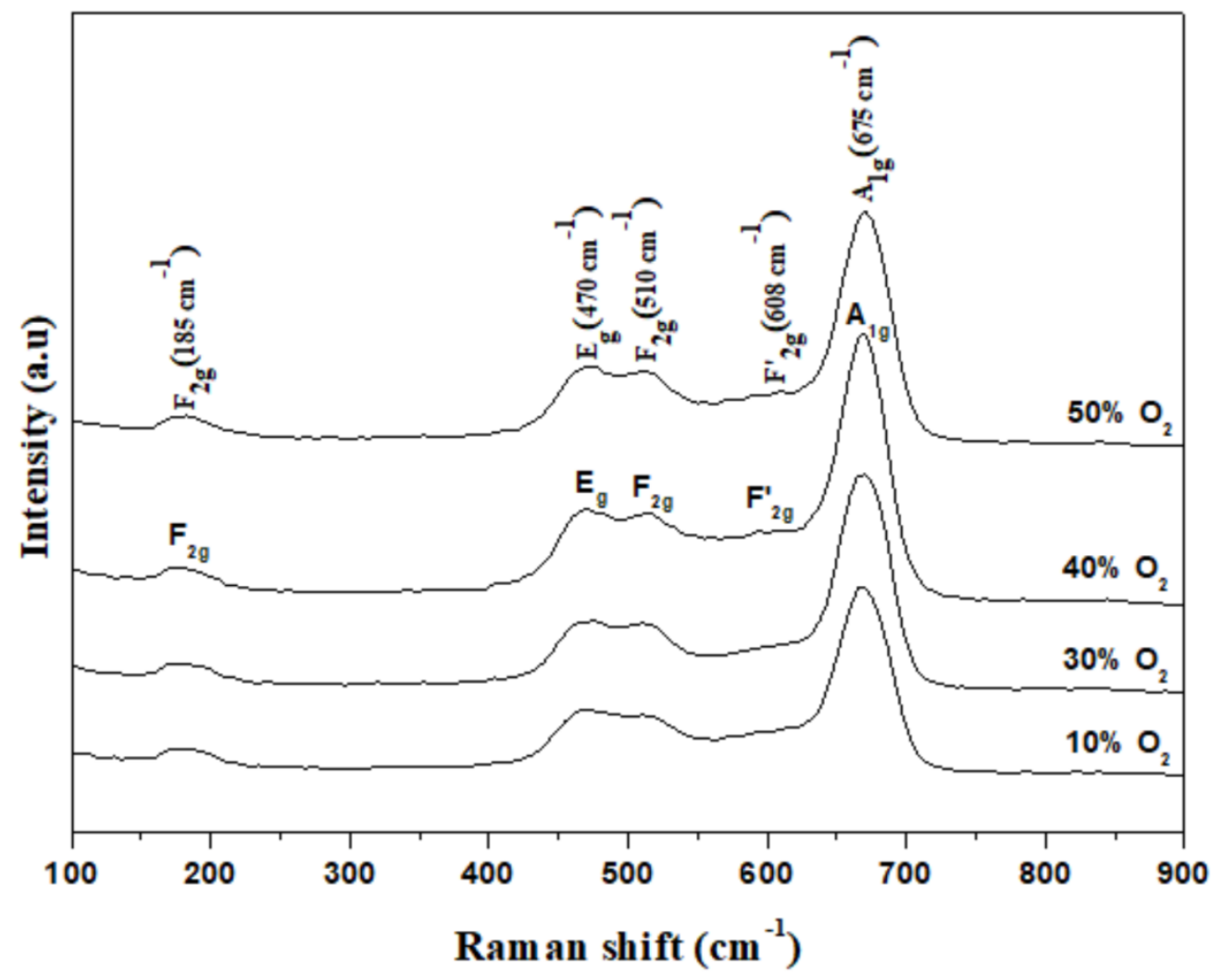

Fig. 5. Raman specta of $\mathrm{Co}_{3} \mathrm{O}_{4}$ film as function of oxygen percentage.

Table 2. Summary of Raman analyses

\begin{tabular}{|c|c|c|c|c|c|c|}
\hline $\begin{array}{c}\text { Oxygen } \\
\text { pressure } \\
(\%)\end{array}$ & $\begin{array}{c}\mathbf{F W H M} \\
\mathbf{0 f} \mathbf{A}_{\mathbf{1 g}}\end{array}$ & $\begin{array}{c}\mathbf{F}_{\mathbf{2 g}} \\
\left(\mathbf{c m}^{-1}\right)\end{array}$ & $\begin{array}{c}\mathbf{E}_{\mathbf{g}} \\
\left(\mathbf{c m}^{-\mathbf{1}}\right)\end{array}$ & $\begin{array}{c}\mathbf{F}_{\mathbf{2 g}} \\
\left(\mathbf{c m}^{-\mathbf{1}}\right)\end{array}$ & $\begin{array}{c}\mathbf{F}_{\mathbf{2 g}} \mathbf{(} \\
\left(\mathbf{c m}^{-\mathbf{1}}\right)\end{array}$ & $\begin{array}{c}\mathbf{A}_{\mathbf{1 g}} \\
\left(\mathbf{c m}^{-\mathbf{1}}\right)\end{array}$ \\
\hline $\mathbf{1 0 \%} \mathbf{O}_{\mathbf{2}}$ & 39.92 & 182 & 467 & 509 & 606 & 668 \\
\hline $\mathbf{3 0 \%} \mathbf{O}_{\mathbf{2}}$ & 37.45 & 183 & 468 & 509 & 607 & 668 \\
\hline $\mathbf{4 0 \%} \mathbf{O}_{\mathbf{2}}$ & 34.35 & 185 & 470 & 510 & 608 & 675 \\
\hline $\mathbf{5 0 \%} \mathbf{O}_{\mathbf{2}}$ & 35.85 & 185 & 472 & 512 & 608 & 675 \\
\hline
\end{tabular}

\subsection{Optical properties}

\subsubsection{Transmittance}

The optical transmittance spectra of the obtained films were recorded in the 400-2500 nm wavelength range and plotted in Fig. 6. It is clear that the transmission of $\mathrm{Co}_{3} \mathrm{O}_{4}$ films increases with increasing oxygen pressure and reached a maximum of $71.5 \%$ in the near IR 
region. This is due in part to the decrease in the thickness of the films sputtered at higher oxygen pressure, which is evident from the profilometer measurements as shown in Table 3 . The reduction of thickness with the increased oxygen pressure reflects the less efficiency of sputtering by oxygen plasma when compared with argon plasma. It may also be possible that more oxygen in the plasma causes the oxidation of the Co target which weakens the sputtering rate. Therefore, the oxygen percentage increases and the transmission of deposited films increase.

Furthermore, two absorption edges can also be clearly distinguished in the transmittance spectra.

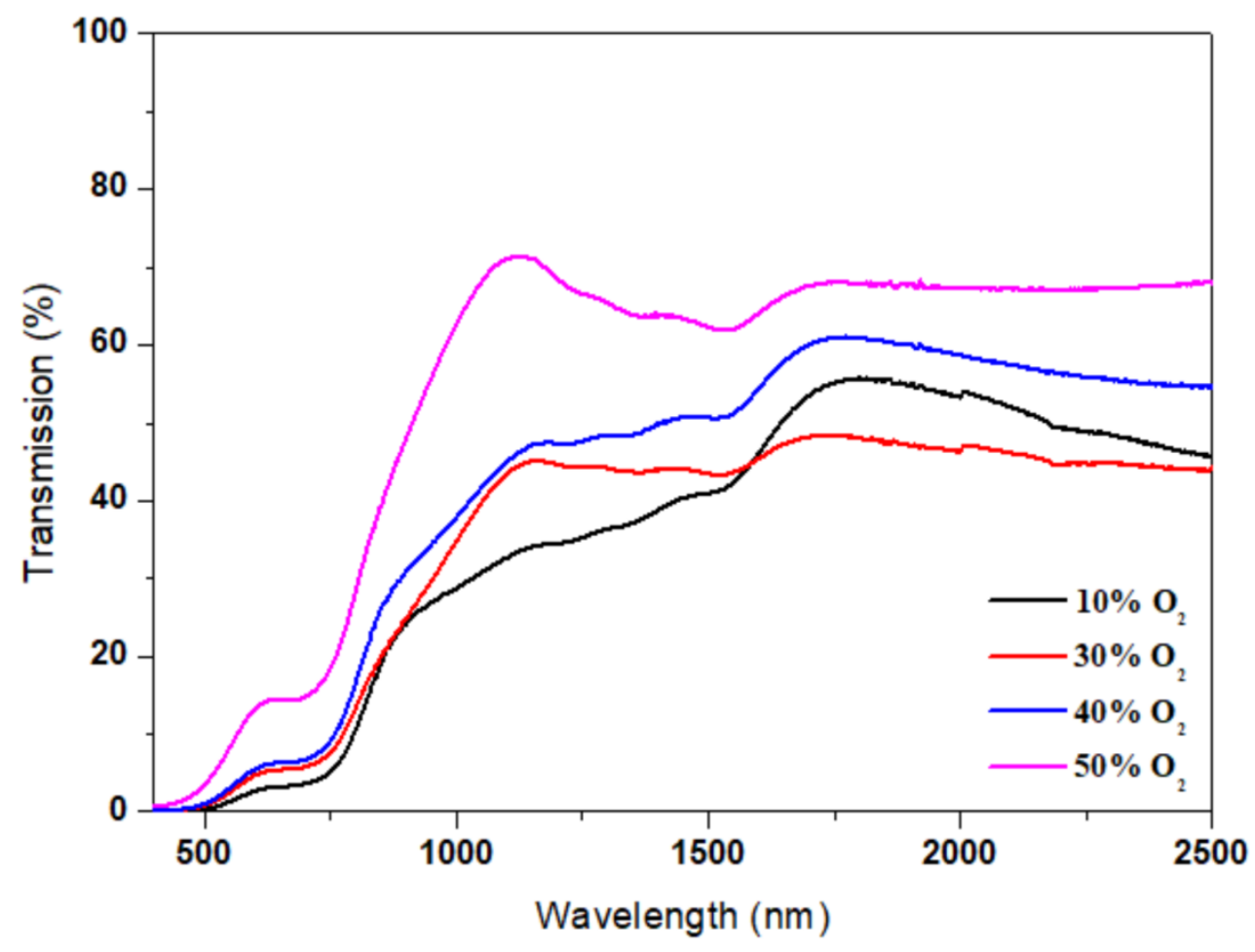

Fig. 6. Transmission spectra of the $\mathrm{CO}_{3} \mathrm{O}_{4}$ nanoparticles at different oxygen percentages.

\subsubsection{Absorption coefficient}

Fig. 7 shows the variation of absorption coefficient, $\alpha$, with photon energy, $h v$, for the $\mathrm{Co}_{3} \mathrm{O}_{4}$ thin films deposited at different oxygen percentages. $\alpha$ obtained by using the Lambert-Beer equation: 


$$
\alpha=\frac{\ln \left(\frac{1}{T}\right)}{e}
$$

where $T$ is the transmission and $e$ is the film thickness. The spectra are characterized by two absorption bands; one is located in the ultra-violet (UV) and the other in the visible (Vis). The first absorption band at $400 \mathrm{~nm}$ is attributed to a "mixed" anion-cation charge transfer from $\mathrm{O}^{2-}\left(2 \mathrm{p}^{6}\right)$ orbitals to $\mathrm{Co}^{2+}$ orbitals $\left(3 \mathrm{~d}^{7}\right)$ and also to $\mathrm{Co}^{3+}$ orbitals $\left(3 \mathrm{~d}^{6}\right)$ [36]. The absorption band around $700 \mathrm{~nm}$ can is attributed to the cation-cation charge transfer between the $\mathrm{d}\left(\mathrm{t}_{2 \mathrm{~g}}\right)$ orbitals of the $\mathrm{Co}^{3+}$ cation in octahedral sites and the $\mathrm{d}\left(\mathrm{t}_{2}\right)$ orbitals of the $\mathrm{Co}^{2+}$ cation in tetrahedral sites.

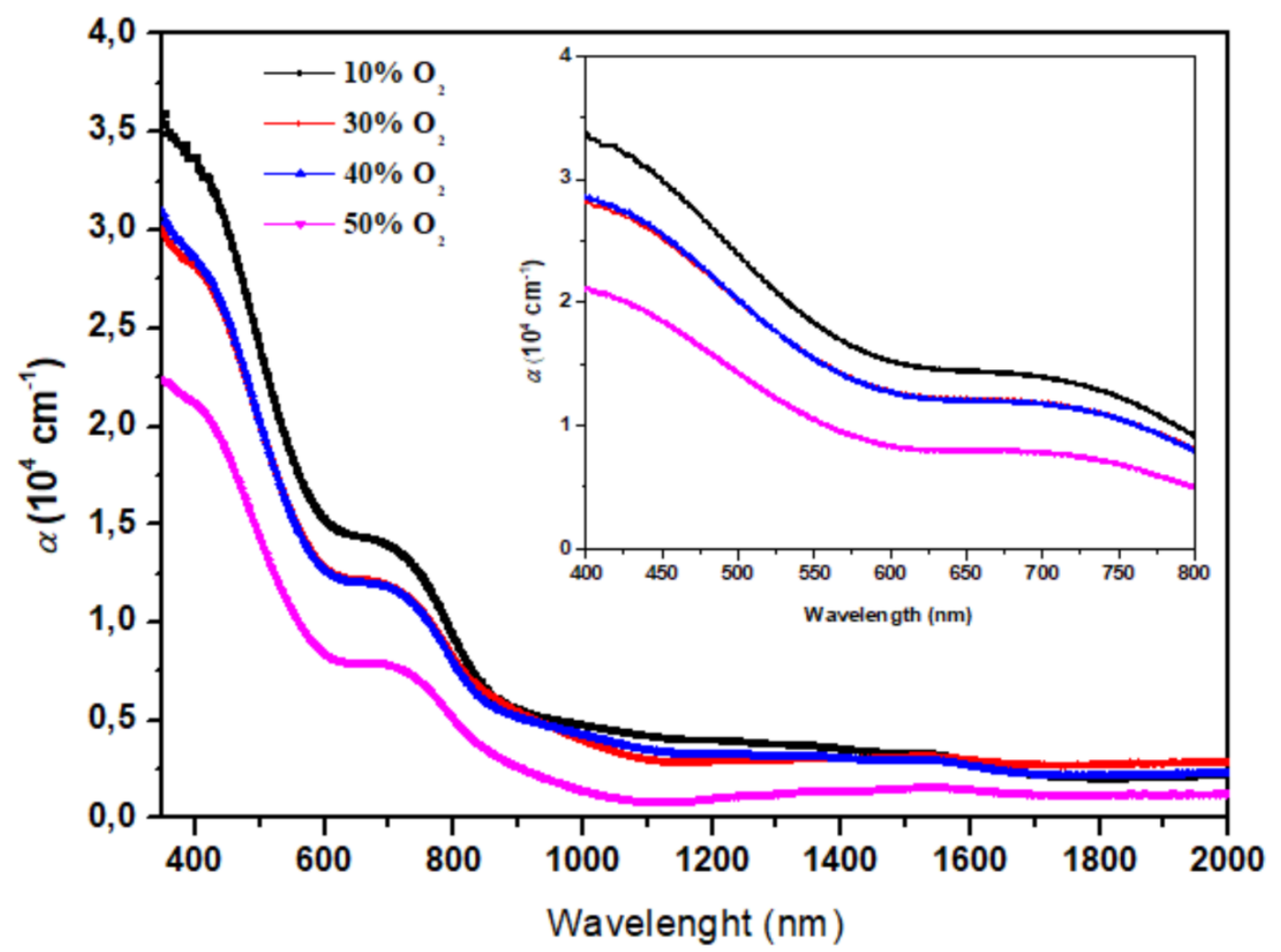

Fig. 7. Absorption spectra of $\mathrm{Co}_{3} \mathrm{O}_{4}$ thin films at different oxygen pressure.

\subsubsection{Optical band gap}

The optical band gap values of the films are determined by the Tauc equation [36]:

$$
(\alpha h v)^{n}=A\left(h v-E_{g}\right)
$$

Where, $A$ is constant, $h v$ is the photon energy, $E_{g}$ is the band gap energy and $n=1 / 2$ for 
indirect transitions and $n=2$ for the direct transitions. Fig. 8 shows plots of $(\alpha h v)^{2}$ as a function of photon energy for the $\mathrm{Co}_{3} \mathrm{O}_{4}$ thin films, which reveal two direct band gaps associated with the two observed absorption fronts. As also shown in table 3 , the two optical gaps increase slightly with oxygen partial pressure during the deposition. The obtained values are in perfect agreement and close to those of bulk $\mathrm{Co}_{3} \mathrm{O}_{4}[36]$.

The existence of two band gaps is well explained in Fig. 9 by the fact that the valence band has a great $\mathrm{O} 2 \mathrm{p}$-character, whereas the principal contribution to the conduction band is given by the $\mathrm{Co}$ (II) $3 \mathrm{~d}$ orbitals [37]. The presence of $\mathrm{Co}$ (III) centers in $\mathrm{Co}_{3} \mathrm{O}_{4}$ gives rise to an intermediate band located inside the energy gap. According to Fig. 8 and 9, the band gap values close to and below $1.5 \mathrm{eV}$ are generally associated with a charge transfer $\mathrm{Co}^{3+} \mathrm{d}\left(\mathrm{t}_{2 \mathrm{~g}}\right)$ $\rightarrow \mathrm{Co}^{2+} \mathrm{d}\left(\mathrm{t}_{2}\right)$ while the values close to and below $2 \mathrm{eV}$, are associated with $\mathrm{O}^{2-}\left(2 \mathrm{p}^{6}\right) \rightarrow \mathrm{Co}^{2+}$ $\left(3 \mathrm{~d}^{7}\right)$ and $\mathrm{O}^{2-}\left(2 \mathrm{p}^{6}\right) \rightarrow \mathrm{Co}^{3+}\left(3 \mathrm{~d}^{6}\right)$ charge transfer. The obtained values are in perfect agreement and close to those of bulk $\mathrm{Co}_{3} \mathrm{O}_{4}$ [36]. One can also notice the increase in band gap with increasing the oxygen pressure (Table 3).
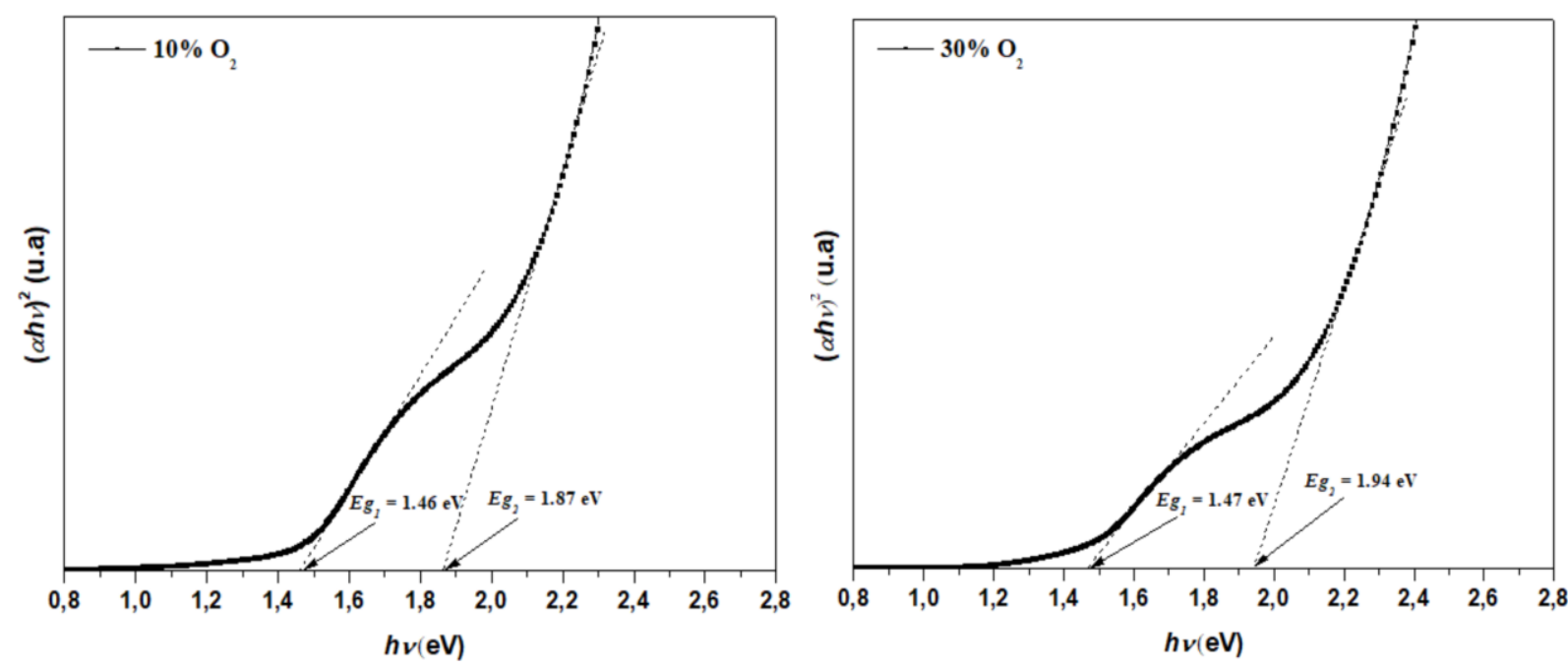

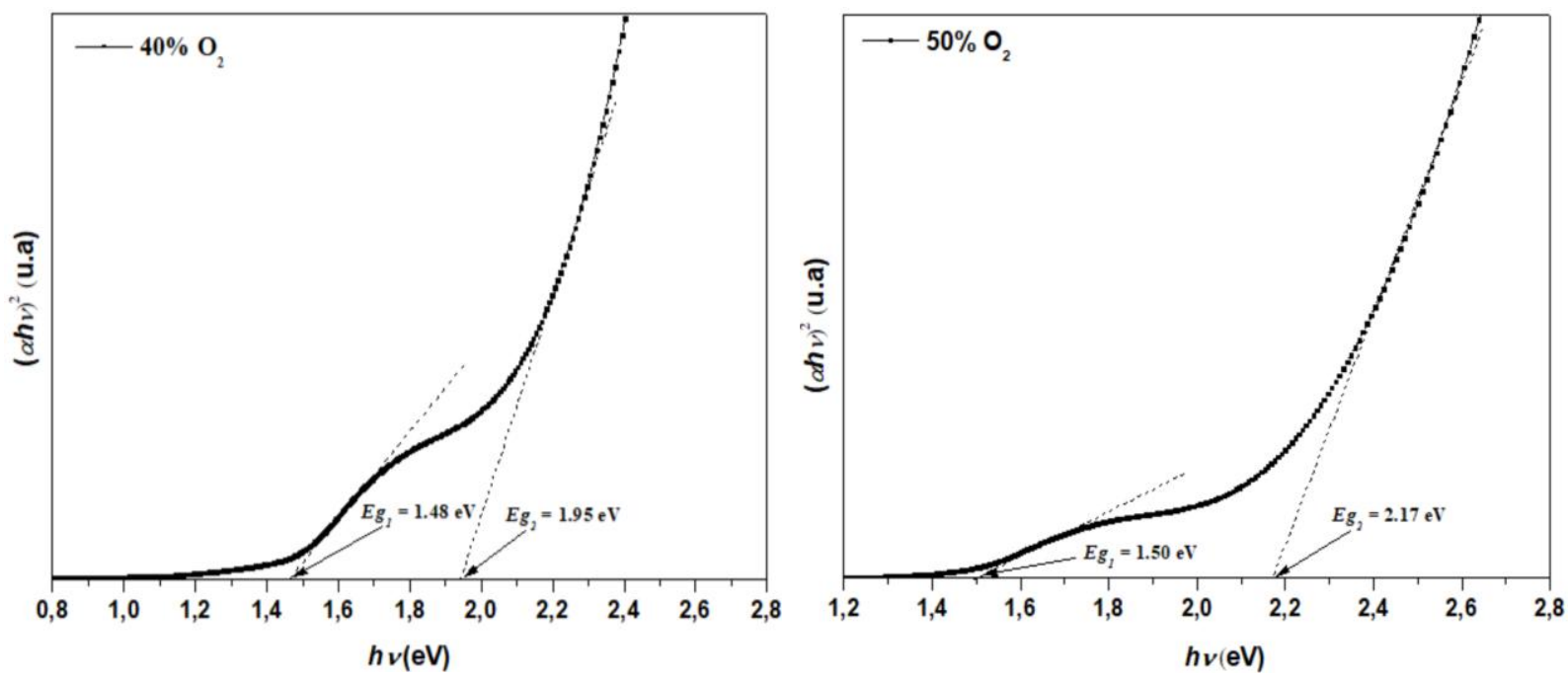

Fig. 8. Plots of $(\alpha h v)^{2}$ as function of $h v$ for $\mathrm{Co}_{3} \mathrm{O}_{4}$ thin films at different oxygen percentages.

Table 3. Optical properties of sputtered thin films at different oxygen pressures.

\begin{tabular}{|c|c|c|c|c|}
\hline \multirow{2}{*}{$\begin{array}{c}\text { Oxygen pressures } \\
(\mathbf{\%})\end{array}$} & \multicolumn{2}{|c|}{$\begin{array}{c}\text { Optical band gap } \\
(\mathbf{e V})\end{array}$} & $\begin{array}{c}\text { Resistivity } \\
(\mathbf{\Omega . c m})\end{array}$ & $\begin{array}{c}\text { Thickness } \\
(\boldsymbol{\mu m})\end{array}$ \\
\cline { 2 - 4 } & $\mathbf{E} \mathbf{E}_{\mathbf{1}}$ & $\mathbf{E g}_{\mathbf{2}}$ & & \\
\hline $\mathbf{1 0}$ & 1.46 & 1.87 & 131.21 & 1.20 \\
\hline $\mathbf{3 0}$ & 1.47 & 1.94 & 197.58 & 1.15 \\
\hline $\mathbf{4 0}$ & 1.48 & 1.95 & 795.63 & 0.97 \\
\hline $\mathbf{5 0}$ & 1.50 & 2.17 & 911.85 & 0.80 \\
\hline
\end{tabular}

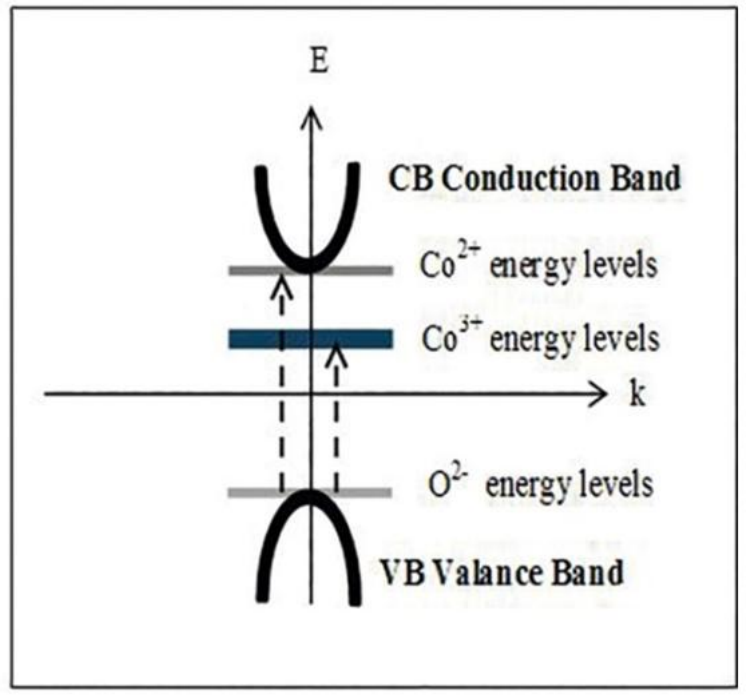

Fig. 9. Schematic representations of the band structure of $\mathrm{Co}_{3} \mathrm{O}_{4}$. 


\subsection{Electrical properties}

The electrical properties of the obtained $\mathrm{Co}_{3} \mathrm{O}_{4}$ thin films at different oxygen percentages were investigated by using the 4-point prob method. The obtained values are given in Table 3 and plotted in Fig. 10. It is found that the resistivity values increases from 131 to $912 \Omega \mathrm{cm}$ as the oxygen percentage is increased. This increase of the resistivity can be explained by an over-stoichiometry in oxygen of the compound which causes an increase of a part of $\mathrm{Co}^{3+}$ in octahedral site to maintain the electroneutrality of the compound [18]. It can also due to the grain boundaries. XRD results suggest an increase in the crystallite size as the oxygen pressure increases. The results are confirmed by AFM measurements which indicate that the grain size increase also which suggest that grain boundary contribution prevails. It is worth noticing that a simple thermoelectric analysis (not shown here) revealed that the prepared $\mathrm{Co}_{3} \mathrm{O}_{4}$ thin films show positive Seebeck coefficient, which is well expected since this material is a p-type semiconductor at room temperature.

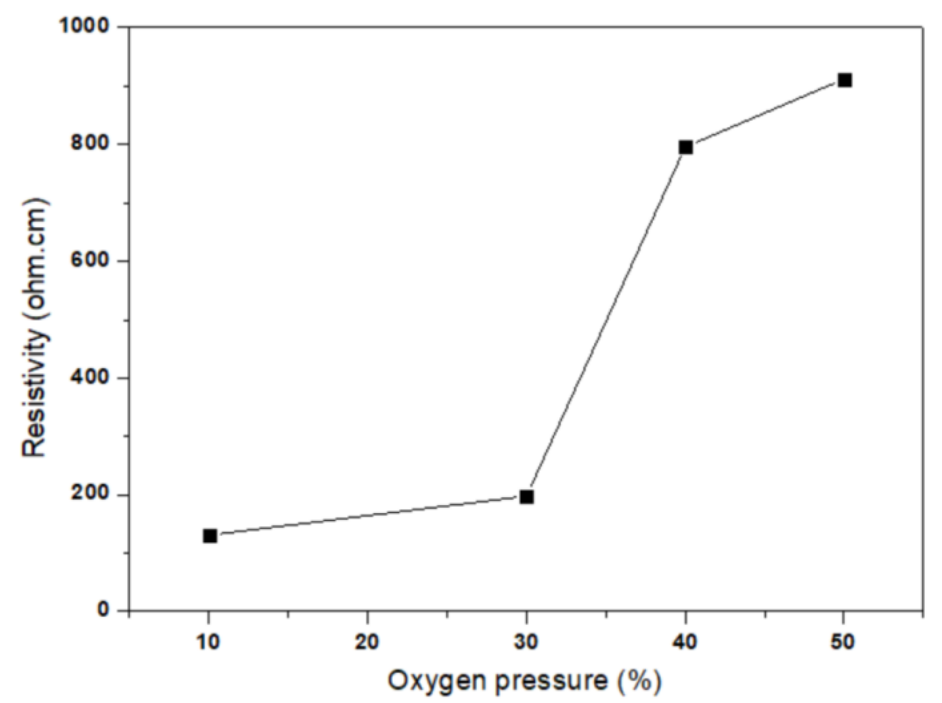

Fig. 10. Resistivity of $\mathrm{Co}_{3} \mathrm{O}_{4}$ thin films as a function of oxygen percentage.

\subsection{Morphological and elemental analysis}

The surface morphology of the sputtered cobalt oxide thin films was also investigated by 
atomic force microscope. Figure 11 presents the atomic force micrographs of $\mathrm{Co}_{3} \mathrm{O}_{4}$ thin films grown at different oxygen pressures. The formed films at $10 \% \mathrm{O}_{2}$ showed a fine grain structure with smooth surfaces. The average grain sizes are 120,130, 150 and $140 \mathrm{~nm}$ for $10 \%, 30 \%, 40 \%$ and $50 \% \mathrm{O}_{2}$ respectively. The root mean square roughness increased from 1.08 to $1.28 \mathrm{~nm}$ with the increasing oxygen pressure reaching $50 \% \mathrm{O}_{2}$. On the other hand, the average surface roughness of the sputtered thin films is $0.69,1.00,1.64$ and 2.35 for $10 \%$, $30 \%, 40 \%$ and $50 \% \mathrm{O}_{2}$ respectively. Such samples can be suitable as a good selective absorber.
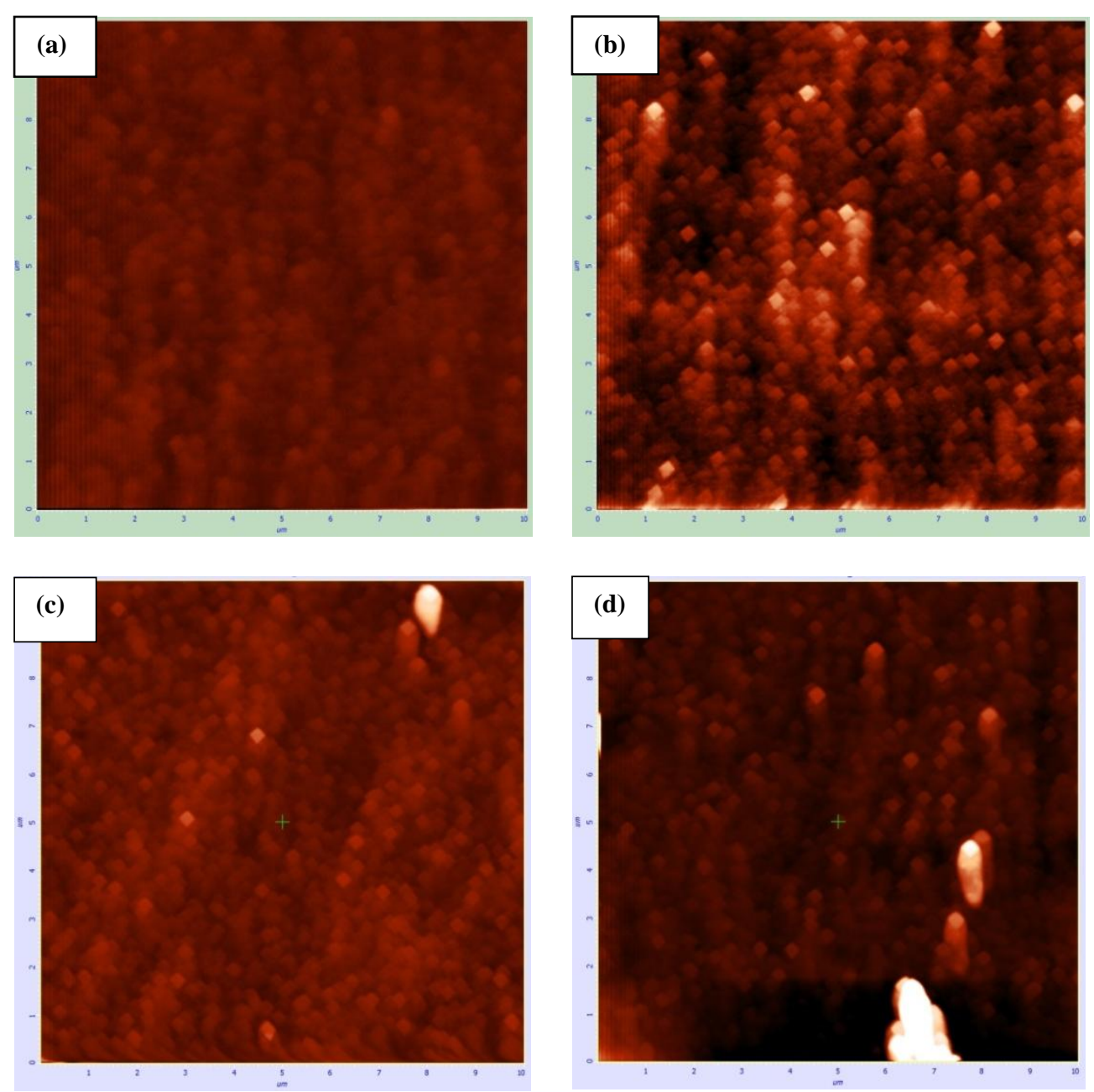

Fig. 11. AFM images of $\mathrm{Co}_{3} \mathrm{O}_{4}$ thin films grown at (a) $10 \%$, (b) $30 \%$, (c) $40 \%$ and (d) $50 \% \mathrm{O}_{2}$.

Table 4 shows the EDX analysis of the elemental composition of cobalt oxide thin films deposited on glass substrate. These measurements have been performed by taking into account only the Co and $\mathrm{O}$ elements. It was found that the amount of Co decreased with 
increasing the oxygen pressure from 10 to $50 \%$, whereas the amount of $\mathrm{O}$ increased with increasing the oxygen pressure. However, the Raman and XRD spectra unequivocally showed that the films are $\mathrm{Co}_{3} \mathrm{O}_{4}$.

Table 4. Elemental composition of $\mathrm{Co}_{3} \mathrm{O}_{4}$ thin films at various oxygen pressures.

\begin{tabular}{|c|c|c|c|}
\hline \multirow{2}{*}{$\begin{array}{c}\text { Oxygen pressure } \\
(\%)\end{array}$} & \multicolumn{2}{|c|}{ Element (weight \%) } & \multirow{2}{*}{ Co/O } \\
\cline { 2 - 3 } & $\mathbf{C o}$ & $\mathbf{O}$ & 1.64 \\
\hline $\mathbf{1 0}$ & 62.1 & 37.9 & 0.89 \\
\hline $\mathbf{3 0}$ & 47.2 & 52.8 & 0.87 \\
\hline $\mathbf{4 0}$ & 46.6 & 53.4 & 0.84 \\
\hline $\mathbf{5 0}$ & 45.7 & 54.3 & \\
\hline
\end{tabular}

\section{Conclusion}

$\mathrm{Co}_{3} \mathrm{O}_{4}$ thin films were successfully deposited by reactive RF-sputtering at different oxygen percentages. The XRD and Raman results showed a pure $\mathrm{Co}_{3} \mathrm{O}_{4}$ phase crystallized in cubic centered face structure with different particles sizes and high surface area. The X-ray reflectometry showed that the obtained density of films tends towards the theoretical value $\mathrm{Co}_{3} \mathrm{O}_{4}\left(6.11 \mathrm{~g} / \mathrm{cm}^{3}\right)$ as the oxygen pressure is increased. The optical properties indicated that the energy gap value depends on the oxygen pressure. Besides, two band gaps 1.46-1.50 eV and 1.87-2.17 eV were observed corresponding to edges of the charge transfer band $\mathrm{Co}^{3+} \rightarrow \mathrm{Co}^{2+}$ and that of oxide ligand to metal $\mathrm{O}^{2-} \rightarrow \mathrm{Co}^{2+}$ and $\mathrm{O}^{2-} \rightarrow \mathrm{Co}^{3+}$ charge transfer band. The electrical conductivity of the sputtered films decreases with the increasing oxygen pressure. These studies confirm that the oxygen pressure strongly affects the properties of cubic structured $\mathrm{Co}_{3} \mathrm{O}_{4}$ thin films. And according to XRD analysis, the $40 \%$ oxygen pressure is therefore considered optimal for the growth of $\mathrm{Co}_{3} \mathrm{O}_{4}$ films with good crystalline quality. We conclude that the RF sputtering allows to obtain uniform film thickness over large areas, a high degree of $\mathrm{Co}_{3} \mathrm{O}_{4}$ films adhesion and makes a good controlling of the quality of $\mathrm{Co}_{3} \mathrm{O}_{4}$ 
thin films in terms of structural, optical and electrical properties for better uses as absorbers in photothermal and photovoltaic applications.

\section{References}

[1] R. . Kodama and R. H., "Magnetic nanoparticles," J. Magn. Magn. Mater., vol. 200, no. 1-3, pp. 359-372, Oct. 1999.

[2] R. W. Siegel, "Cluster-Assembled Nanophase Materials," Annu. Rev. Mater. Sci., vol. 21, no. 1, pp. 559-578, Aug. 1991.

[3] H. Gleiter, "Nanocrystalline materials," Prog. Mater. Sci., vol. 33, no. 4, pp. 223-315, Jan. 1989.

[4] X. Zhu, J. Wang, D. Nguyen, J. Thomas, R. A. Norwood, and N. Peyghambarian, "Linear and nonlinear optical properties of Co_3O_4 nanoparticle-doped polyvinyl-alcohol thin films," Opt. Mater. Express, vol. 2, no. 1, p. 103, Jan. 2012.

[5] L. P. Oleksenko, N. P. Maksymovych, A. I. Buvailo, I. P. Matushko, and N. Dollahon, "Adsorption-semiconductor hydrogen sensors based on nanosized tin dioxide with cobalt oxide additives," Sensors Actuators B Chem., vol. 174, no. 174, pp. 39-44, Nov. 2012.

[6] S. G. Kandalkar, J. L. Gunjakar, and C. D. Lokhande, "Preparation of cobalt oxide thin films and its use in supercapacitor application," Appl. Surf. Sci., vol. 254, no. 17, pp. 5540-5544, Jun. 2008.

[7] J. Wöllenstein, M. Burgmair, G. Plescher, T. Sulima, J. Hildenbrand, H. Böttner, I. Eisele, "Cobalt oxide based gas sensors on silicon substrate for operation at low temperatures," Sensors Actuators B Chem., vol. 93, no. 1-3, pp. 442-448, Aug. 2003.

[8] P. S. Patil, L. D. Kadam, and C. D. Lokhande, "Preparation and characterization of spray pyrolysed cobalt oxide thin films," Thin Solid Films, vol. 272, no. 1, pp. 29-32, Jan. 1996.

[9] A. Avila G., E. Barrera C., L. Huerta A., and S. Muhl, "Cobalt oxide films for solar selective surfaces, obtained by spray pyrolisis," Sol. Energy Mater. Sol. Cells, vol. 82, no. 1-2, pp. 269278, May 2004.

[10] C. Benel, A. Darbandi, R. Djenadic, A. Evans, R. Tölke, M. Prestat, H. Hahn, "Synthesis and characterization of nanoparticulate $\mathrm{La} 0.6 \mathrm{Sr} 0.4 \mathrm{CoO} 3-\delta$ cathodes for thin-film solid oxide fuel cells," J. Power Sources, vol. 229, pp. 258-264, May 2013.

[11] C. Guyon, A. Barkallah, F. Rousseau, K. Giffard, D. Morvan, and M. Tatoulian, "Deposition of cobalt oxide thin films by plasma-enhanced chemical vapour deposition (PECVD) for catalytic applications," Surf. Coatings Technol., vol. 206, no. 7, pp. 1673-1679, Dec. 2011.

[12] J.-S. Do and C.-H. Weng, "Preparation and characterization of $\mathrm{CoO}$ used as anodic material of lithium battery," J. Power Sources, vol. 146, no. 1-2, pp. 482-486, Aug. 2005.

[13] M. Roy, S. Ghosh, and M. K. Naskar, "Ligand-assisted soft-chemical synthesis of selfassembled different shaped mesoporous $\mathrm{Co}_{3} \mathrm{O}_{4}$ : efficient visible light photocatalysts," Phys. Chem. Chem. Phys., vol. 17, no. 15, pp. 10160-10169, Apr. 2015.

[14] S. A. Makhlouf, "Magnetic properties of Co3O4 nanoparticles," J. Magn. Magn. Mater., vol. 246, no. 1-2, pp. 184-190, Apr. 2002. 
[15] Y. F. Zheng, L. Wang, and X. C. Song, "Electrochromic properties of nanoporous Co3O4 thin films prepared by electrodeposition method," Micro Nano Lett., vol. 7, no. 10, pp. 1026-1029, Oct. 2012.

[16] A. H. Jayatissa, K. Guo, A. C. Jayasuriya, and T. Gupta, "Fabrication of nanocrystalline cobalt oxide via sol-gel coating," Mater. Sci. Eng. B, vol. 144, no. 1-3, pp. 69-72, Nov. 2007.

[17] R. Drasovean, R. Monteiro, E. Fortunato, and V. Musat, "Optical properties of cobalt oxide films by a dipping sol-gel process," J. Non. Cryst. Solids, vol. 352, no. 9-20, pp. 1479-1485, Jun. 2006.

[18] C.-S. Cheng, M. Serizawa, H. Sakata, and T. Hirayama, "Electrical conductivity of Co3O4 films prepared by chemical vapour deposition," Mater. Chem. Phys., vol. 53, no. 3, pp. 225230, Jun. 1998.

[19] M. Manickam, V. Ponnuswamy, C. Sankar, and R. Suresh, "Cobalt oxide thin films prepared by NSP technique: Impact of molar concentration on the structural, optical, morphological and electrical properties," Opt. - Int. J. Light Electron Opt., vol. 127, no. 13, pp. 5278-5284, Jul. 2016.

[20] C. L. Liao, Y. H. Lee, S. T. Chang, and K. Z. Fung, "Structural characterization and electrochemical properties of RF-sputtered nanocrystalline Co3O4 thin-film anode," J. Power Sources, vol. 158, no. 2, pp. 1379-1385, Aug. 2006.

[21] B. Li, X. Wang, M. Yan, and L. Li, "Preparation and characterization of nano-TiO2 powder," Mater. Chem. Phys., vol. 78, no. 1, pp. 184-188, Feb. 2003.

[22] H. H. Yudar, Ş. Korkmaz, S. Özen, V. Şenay, and S. Pat, "Surface and optical properties of indium tin oxide layer deposition by RF magnetron sputtering in argon atmosphere," Appl. Phys. A, vol. 122, no. 8, p. 748, Aug. 2016.

[23] A. Louardi, A. Rmili, F. Ouachtari, A. Bouaoud, B. Elidrissi, and H. Erguig, "Characterization of cobalt oxide thin films prepared by a facile spray pyrolysis technique using perfume atomizer," J. Alloys Compd., vol. 509, no. 37, pp. 9183-9189, Sep. 2011.

[24] F. Bayansal, T. Taşköprü, B. Şahin, and H. A. Çetinkara, "Effect of cobalt doping on nanostructured $\mathrm{CuO}$ thin films," Metall. Mater. Trans. A Phys. Metall. Mater. Sci., vol. 45, no. 8, pp. 3670-3674, 2014.

[25] M. Saleem, L. Fang, A. Wakeel, M. Rashad, and C. Y. Kong, "Simple Preparation and Characterization of Nano-Crystalline Zinc Oxide Thin Films by Sol-Gel Method on Glass Substrate," World J. Condens. Matter Phys., vol. 02, no. 01, pp. 10-15, Feb. 2012.

[26] B. L. Henke, E. M. Gullikson, and J. C. Davis, "X-Ray Interactions: Photoabsorption, Scattering, Transmission, and Reflection at E $=50-30,000 \mathrm{eV}, \mathrm{Z}=1-92$, " At. Data Nucl. Data Tables, vol. 54, no. 2, pp. 181-342, Jul. 1993.

[27] Y. Fujii, "Recent Developments in the X-ray Reflectivity Analysis," Am. J. Phys. Appl., vol. 4, no. 2, p. 27, Mar. 2016.

[28] M. Shiojiri, Y. Saito, H. Okada, and H. Sasaki, "Desities of Amorphous Thin Films," Jpn. J. Appl. Phys., vol. 18, no. 10, pp. 1931-1936, Oct. 1979.

[29] D. L. Gil and D. Windover, "Limitations of x-ray reflectometry in the presence of surface contamination," J. Phys. D. Appl. Phys., vol. 45, no. 23, p. 235301, Jun. 2012.

[30] C.-T. Ho, T.-H. Weng, C.-Y. Wang, S.-J. Yen, and T.-R. Yew, "Tunable band gaps of Co $3-x$ $\mathrm{Cu} \times \mathrm{O}_{4}$ nanorods with various $\mathrm{Cu}$ doping concentrations," $R S C A d v$., vol. 4, no. 38, pp. 
20053-20057, Apr. 2014.

[31] V. G. Hadjiev, M. N. Iliev, and I. V Vergilov, “The Raman spectra of $\mathrm{Co}_{3} \mathrm{O}_{4}$," J. Phys. C Solid State Phys., vol. 21, no. 7, pp. L199-L201, Mar. 1988.

[32] A. Diallo, A. C. Beye, T. B. Doyle, E. Park, and M. Maaza, "South Africa; b Nanosciences African Network (NANOAFNET), iThemba LABS-National Research Foundation, 1 Old Faure road," 2015.

[33] J. Jiang and L. Li, "Synthesis of sphere-like Co3O4 nanocrystals via a simple polyol route," Mater. Lett., vol. 61, no. 27, pp. 4894-4896, Nov. 2007.

[34] L. Popović, D. de Waal, and J. C. A. Boeyens, "Correlation between Raman wavenumbers and P?O bond lengths in crystalline inorganic phosphates," J. Raman Spectrosc., vol. 36, no. 1, pp. 2-11, Jan. 2005.

[35] V. G. Hadjiev, M. N. Iliev, and I. V Vergilov, "The Raman spectra of $\mathrm{Co}_{3} \mathrm{O}_{4}$," J. Phys. C Solid State Phys., vol. 21, no. 7, pp. L199-L201, Mar. 1988.

[36] D. Barreca, C. Massignan, S. Daolio, M. Fabrizio, C. Piccirillo, L. Armelao, E. Tondello, "Composition and Microstructure of Cobalt Oxide Thin Films Obtained from a Novel Cobalt(II) Precursor by Chemical Vapor Deposition," Chem. Mater., vol. 13, no. 2, pp. 588593, Feb. 2001.

[37] A. Lakehal, B. Bedhiaf, A. Bouaza, B. Hadj, A. Ammari, C. Dalache, "Structural, optical and electrical properties of Ni-doped Co3O4 prepared via Sol-Gel technique," Mater. Res., vol. 21, no. 3, Feb. 2018. 